\title{
研究所紹介
}

\section{Ernest Orlando Lawrence Berkeley National Laboratory - Fundamental and Applied Research on Lean Premixed Combustion}

\author{
Robert K. Cheng \\ Group Leader - Combustion Technologies \\ Environmental Energy Technologies Division
}

\section{Introduction}

Ernest Orlando Lawrence Berkeley National Laboratory (Berkeley Lab) is the oldest of America's national laboratories and has been a leader in science and engineering technology for more than 65 years, serving as a powerful resource to meet US national needs. As a multiprogram Department of Energy laboratory, Berkeley Lab is dedicated to performing leading edge research in the biological, physical, materials, chemical, energy, environmental and computing sciences. It is situated in Berkeley, California 15 miles east of San Francisco and is located on 130 acres in the hills overlooking the campus of the University of California at Berkeley (Figure 1). Like other national laboratories in the United States, Berkeley Lab is primarily funded by the U.S. Department of Energy. The Department of Energy has contracted with the University of California system to manage the Laboratory. Charles V. Shank, the inventor of the femtosecond laser, is the Lab's director.

Ernest Orlando Lawrence, the Lab's founder and the first of its nine Nobel prize winners, invented the cyclotron, which led to a Golden Age of particle physics and revolutionary

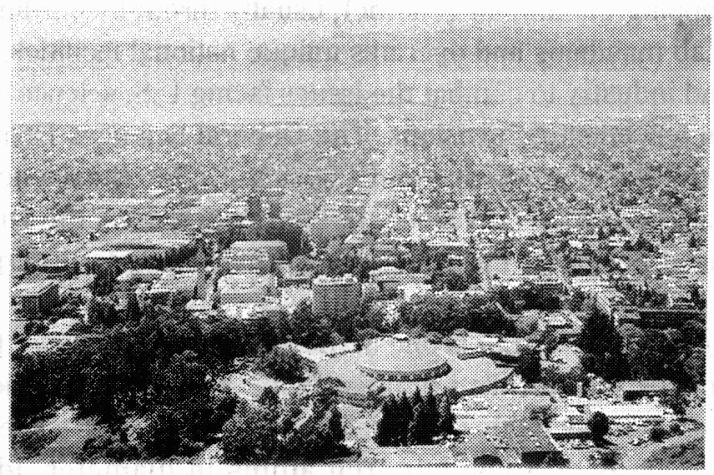

Fig. 1. Berkeley Lab affords a panoramic view of the San Francisco Bay with the Gold Gate Bridge in the distant background. 
discoveries about the nature of the universe. To this day, the Lab remains a world center for accelerator and detector innovation and design. The Lab is the birthplace of nuclear medicine and the cradle of invention for medical imaging. In the field of heart disease, Lab researchers were the first to isolate lipoproteins and the first to determine that the ratio of high density to low density lipoproteins is a strong indicator of heart disease risk. The demise of the dinosaurs - the revelation that they had been killed off by a massive comet or asteroid that had slammed into the Earth - was a theory developed here. The invention of the chemical laser, the unlocking of the secrets of photosynthesis .... this is a short preview of the legacy of this Laboratory.

Research here ranges across the panorama of science. Lab scientists are among the pioneers who are helping build the Internet, at one point preventing its collapse by developing protocols to regulate traffic flow on the net. Life scientists have developed a mouse model that will allow testing of experimental treatments for human sickle cell disease. Astrophysicists are on the verge of resolving age-old questions about how our universe was created and whether it will one day end. Material scientists are working at the frontier of atomic scale engineering. Fuel cells and combustion devices are being developed and better lighting is moving from our labs into the marketplace.

Berkeley Lab interacts with the private sector in a growing number of collaborative research projects intended to transfer research know-how into the national economy. A number of corporations supply both funding and expertise for many joint projects that range from building the next generation of semiconductors to developing new tests for heart disease risk to the development of new materials for industry.

Although Berkeley Lab's function is to conduct research, the workforce includes a diverse range of professions. Berkeley Lab employs a total of about 3,500. Among these are 1,300 scientists and engineers including some 240 faculty members from University of California at Berkeley and similar academic institutions, some 500 managers and administrators, and 1,700 technical and support staff members. In addition to the fulltime workforce, the Lab plays host each year to nearly 2,000 guest researchers from the U.S. and abroad. More information can be found on our web-site (http://www.lbl.gov).

\section{Berkeley Lab Research Divisions}

Berkeley Lab has been a pioneer of interdisciplinary science. Today, Berkeley Lab scientists attacks problems of scale (high-performance computing, environment, energy, energy efficiency, mapping the human genome), usually through coordinated interdisciplinary research. Berkeley Lab maintains and operates unique national facilities, and serves as a focal point for academia and industry to combat the issues facing U.S. science and technology.

Berkeley Lab has ten scientific divisions. The General Sciences Divisions are Accelerator and Fussion Research, Nuclear Science and Physics. Under Biosciences, we have the Life Sciences and Physical Biosciences Divisions. In Energy Sciences, the Divisions are Advanced Light Source, Chemical Sciences, Earth Sciences, Environmental Energy Technologies and Material Sciences.

The Advanced Light Source (ALS) is one of the leading national user facilities, The ALS, an accelerator that produces the world's brightest "soft" X-ray and ultraviolet light, debuted in 1993, serving scientists in many fields. Materials scientists use it as a spectroscopic probe that can focus on surface areas of a few hundred atoms in diameter, identifying elemental compositions and their electron structures. Chemists employ a camera to study basic chemical reactions related to complex phenomena such as combustion. Biologists and other life 
scientists use it as an x-ray microscope that can peer into living cells in their natural state and perhaps provide the first truly three-dimensional images of the structures within.

Berkeley Lab is also the home of NERSC, the National Energy Research Scientific Computing Center. NERSC is the most powerful unclassified computing center in the United States. NERSC is in the process of demonstrating that computing is a tool as vital as experimental and theoretical sciences in solving the scientific challenges of the twenty-first century. By taking full advantage of large scale computing, energy research will benefit from a rate of progress previously unknown. In order to achieve these goals, NERSC is in the midst of creating the world's most unique integration of state-of-the-art high performance computing and networking facilities with world class computational and computer science programs. These are all collocated at Berkeley Lab that is itself a microcosm of the physical and life sciences communities that constitute NERSC's focus. Research on more efficient and less polluting combustion, Earth's climate changes, and engineering shape of molecule to perform targeted biological function are examples of NERSC's current activities. As a necessary process in conducting the research, these activities also pioneer the future of computing itself - hardware, software, and networks destined to be increasingly important to our daily lives.

\section{Environmental Energy Technologies Division}

Berkeley Lab's Combustion Technologies Group is within the Advanced Energy Technology Department of the Environmental Energy Technologies Division (EET). EET Division engages in applied and fundamental research on technologies that use, convert and store energy more efficiently and with less environmental impact, and studies the link between energy use and the environment. An important outcome of its work is the development of technologies and processes to mitigate the environmental effects of energy use. The EET Division was established in 1973 in response to concerns about the cost, availability, and environmental effects of energy. Major areas of research in the EET Division are:

Energy Efficiency in Buildings

Energy-efficient windows and daylighting systems

Energy-efficient lighting concepts and systems

Simulation tools for energy use in buildings

Information technology for energy efficiency in commercial buildings

Application of advanced concepts to testbed buildings

Indoor Environment

Advanced ventilation, infiltration, and thermal distribution systems

Sources, emissions, and transport of indoor pollutants

Air pollutant exposures and health risks

Control strategies for indoor air quality

U.S. Energy Issues

Appliance and equipment energy-efficiency standards

Energy efficiency programs to promote market transformation

Energy utility deregulation

End-use energy demand forecasting and policy analysis

International Energy Issues

Energy efficiency in developing countries (special emphasis: China and India)

Energy efficiency and global climate change 


\section{Advanced Energy Technologies}

Electrochemical research on batteries

Combustion and emissions

Laser and other spectroscopic tools: development and application

Over the years, EET Division has responded to evolving national and international concerns. A major area of research is making residential and commercial buildings more energy-efficient, and maximizing the health and productivity of building occupants. EET Division achievements in this area include developing energy-efficient windows and energyefficient electronic ballasts for use with fluorescent lights, in cooperation with window and lighting industries. These technologies now save billions of dollars a year in energy costs, and reduce the emissions of millions of tons of gases from fossil fuel burning. Creating major software tools for better building design is another contribution of EET Division. These tools help architects and engineers design safe, comfortable, energy-efficient buildings. Scientists in EET Division also conduct laboratory experiments to understanding indoor air quality problems and developing solutions.

Another major focus is analysis of energy efficiency policies and programs in the United States and internationally. The U.S. Department of Energy uses the research of the Division in developing appliance energy standards. EETD has also made significant contributions to international organizations, including the Inter-governmental Panel on Climate Change, with studies of measures to reduce greenhouse gas emissions. Other research examines industrial and transportation energy use. Also underway are research and analysis programs on energy efficiency in key developing countries, especially China and India. The Division also conducts air quality research. One of the products of its long-standing interest in indoor environmental quality is a body of research on the physics and health effects of radioactive radon gas in homes, which has contributed important input to the efforts of regulatory agencies to reduce radon hazard. EETD is a leader in building ventilation and infiltration studies. Other work focuses on measuring and modeling atmospheric chemistry, human exposures to and transport processes of airborne pollutants, particulates in the air, and contaminants such as gaseous emissions from new building materials.

Research in advanced energy technologies encompasses advanced batteries and fuel cells for electric and hybrid vehicles, methods of enhancing bioremediation and industrial processes, and novel materials that have possible applications as superconductors or photovoltaic devices. Other work is directed toward studying the biological effects of pollutants related to energy generation, and developing cleaner and more efficient combustion processes for diesel engines, water heaters and boilers, and gas turbines.

EETD Facilities include laboratories devoted to developing energy-efficient lighting systems, energy-efficient window systems, advanced energy technology (batteries and fuel cells), geographic information systems, the combustion lab, an environmental chamber for the study of indoor pollutants, and a field facility for testing advanced windows and insulators. The major research funder is the U.S. Department of Energy. Others include the U.S. Environmental Protection Agency, the U.S. Agency for International Development, industrial partners, the California Institute for Energy Efficiency, and state and local governments.

\section{Combustion Research Laboratory}

The Combustion Research Laboratory at Berkeley Lab conduct basic and applied research on lean turbulent premixed combustion. This combustion method is fast becoming an 
important environmental energy technology because it is a simple and effective means to prevent the formation of oxides of nitrogen. Many US manufacturers of heating equipment are developing premixed burners for their heating products. For power generation, lean premixed combustors are being used in gas turbines both large and small. The goal of our research program is to investigate and characterize fundamental fluid processes of flame/turbulence interaction and to apply the knowledge to the development of combustion theories and numerical simulations ${ }^{(1) \cdot(4)}$. We also specialize in the development of novel lean premixed burner concepts ${ }^{(5),(6)}$ and perform applied research to further exploit the potential of using these new burner concepts in practical systems ${ }^{(7),(8)}$.

\section{Basic Research}

Understanding flame/turbulence interaction is considered one of today's most challenging combustion research problems. Turbulence is known to influence combustion efficiency, flame stability, blow-off and formation of pollutants. Since 1977, the Berkeley Lab's Combustion Technologies Group has been developing innovative laboratory experiments to characterize and understand flame/turbulence interaction processes from a fluid mechanical perspective. These experiments are designed to enable a systematic variation of flow velocities, turbulence intensities, turbulence scales and mixture characteristics (i.e. fucl type and equivalence ratios). Also emphasize are studies of the influence of flame geometry on turbulent flame features and behavior. Figure 2 shows four different burner configurations that we have used. These laboratory burners are designed specifically to allow free access for laser diagnostics. Their flame geometries are suitable for direct comparison to current numerical simulations and theoretical analysis.

We use advanced laser diagnostics to measure flow velocity and scalar statistics. Since stable statistical information is sought, we employ relatively well-established diagnostics such as laser Doppler anemometry, tomography, and planar laser induced fluorescence. Collecting a reliable and stable set of statistical data requires a long period and repeated runs. Consequently, all our experiments are fully computerized to minimize run time and run-to run

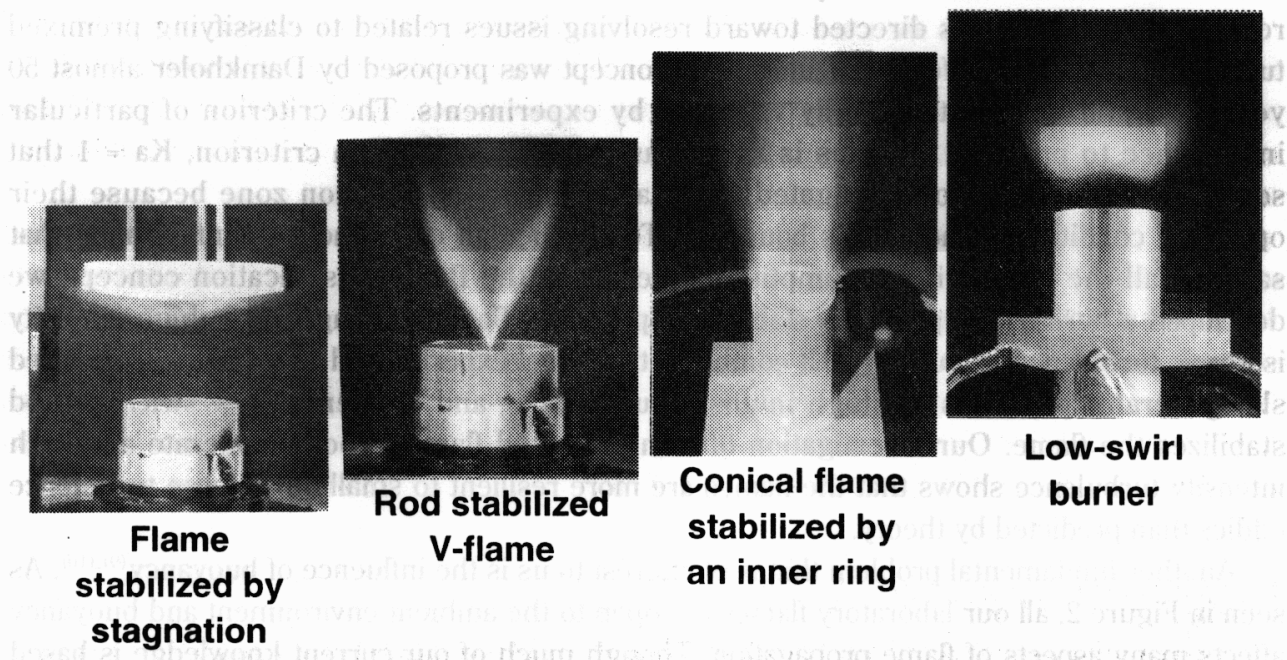

Fig. 2. Laboratory turbulent premixed flame configurations studied at Berkeley Lab. 


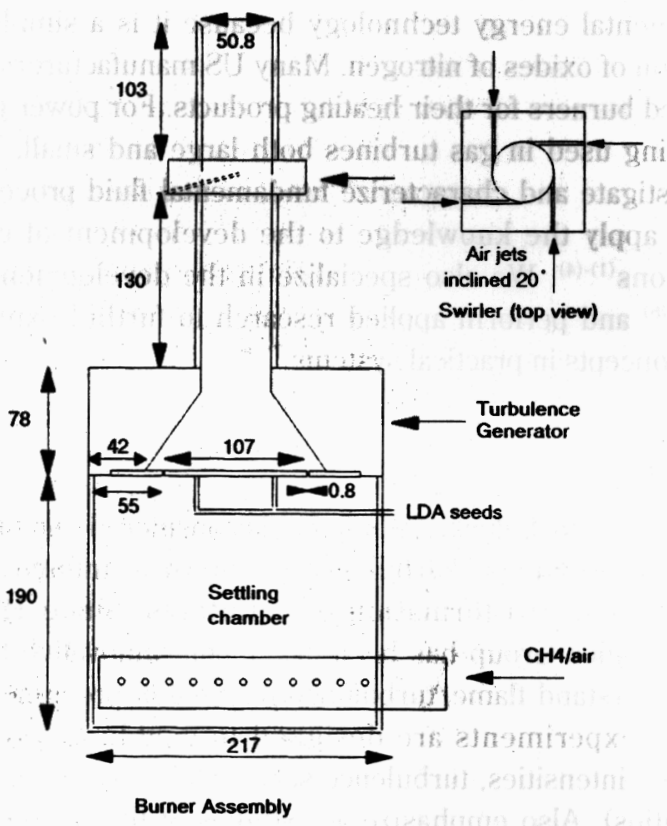

Fig. 3. Schematics of the low-swirl burner with a circular slot turbuelnce generator

variations. The availability of computerized experiments also allows us to perform unique procedures such as flowline tracing ${ }^{(3)}$ and high speed tomography (up to 2000 frames per second $)^{(4)}$. These capabilities have help to advance our understanding of the complex flame turbulence interactions. To compliment our experimental endeavor, we conduct numerical simulation, and collaborate with US and international scientists to develop theoretical models.

Our established experimental database of premixed turbulent flames is accessible to other researchers and has been used by many to validate their turbulent combustion models. Our recent research effort is directed toward resolving issues related to classifying premixed turbulent flames into different regimes. The concept was proposed by Damkholer almost 50 years ago and has yet to be fully validated by experiments. The criterion of particular importance to practical systems is known as the Klimov-William criterion, Ka $=1$ that separates the regimes of corrugated flame and distributed reaction zone because their operating conditions straddle this boundary. To produce an experimental configuration that satisfies all the underlying assumptions inherent in the flame classification concept, we developed a burner that produces stable lean premixed flames propagating in high intensity isotropic turbulence (Figure 3$)^{(1)}$. It combines two novel experimental concepts; a specialized slot generator produces the high intensity turbulence, and a patented low swirl method stabilizes the flame. Our investigation of lean premixed flame in both moderate and high intensity turbulence shows that the flames are more resilient to small but intense turbulence eddies than predicted by theory.

Another fundamental problem that is of interest to us is the influence of buoyancy ${ }^{(9),(10)}$. As seen in Figure 2, all our laboratory flames are open to the ambient environment and buoyancy affects many aspects of flame propagation. Though much of our current knowledge is based on observations made in these open flames, the effects of buoyancy are usually not included in 


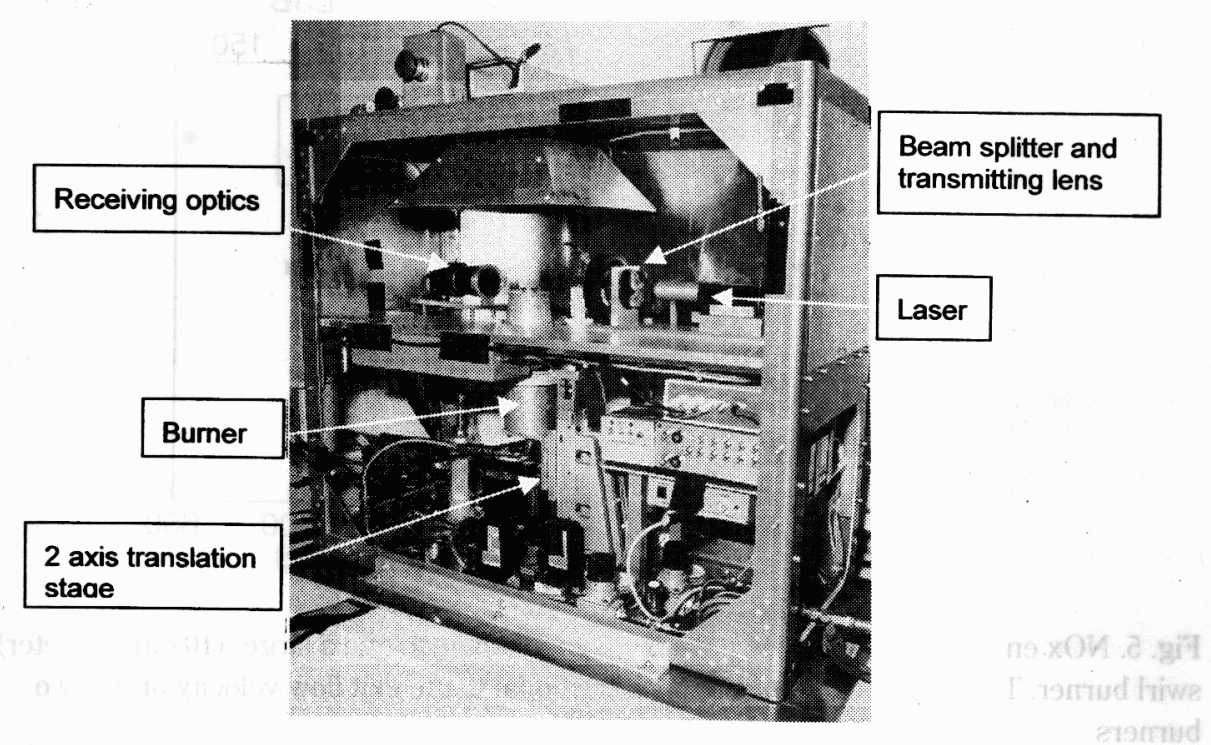

Fig. 4. Experimental package for microgravity aircraft experiment with LDA optics

data interpretation, numerical analysis or theories. This inconsistency remains an obstacle to merging experimental observations and theoretical predictions. To better understanding the effects of buoyancy, we compare flames in normal gravity $(+1 g)$, reversed gravity $(-1 g)$ and in microgravity $(\mu \mathrm{g})$. Our $\mu \mathrm{g}$ experiments are conducted using a self-contain "package" shown in Figure 4. This unit is essentially a miniaturization of our laboratory experiment equipped with laser Doppler anemometry, flow controls and traversing devices. We hypothesize that the most significant role of buoyancy forces on these flames is to influence their flowfields through a coupling with mean and fluctuating pressure fields. Therefore, buoyancy has the same significance as other parameters such as flow configuration, flame geometry, means of flame stabilization, flame shape, enclosure size, mixture conditions, and flow conditions. Investigations of rod-stabilized v-flames subjected to $+1 \mathrm{~g}$ and $-1 \mathrm{~g}$ have lead to the discovery of new turbulent flame phenomena ${ }^{(9)}$ and to more open questions ${ }^{(10)}$. In particular, we found that the effects of buoyancy in turbulent flames persist beyond the limit predicted by current scaling laws.

\section{Applied Research}

Our accomplishment in applying scientific knowledge to technology development is a testament to the value of our basic research. In developing laboratory experiments, we routinely consider different burner designs that enable the investigations of lean premixed turbulent flames under near limit conditions. Some research burners have very little practical relevance (e.g. the stagnation flow burner shown to the left of Figure 2). Two other burners have been found to be directly applicable to a variety of heating and power generating systems. Their unique capability to stabilize ultra-lean flames with close to $100 \%$ combustion efficiency can be exploited for next-generation low emission combustion systems. The conical 


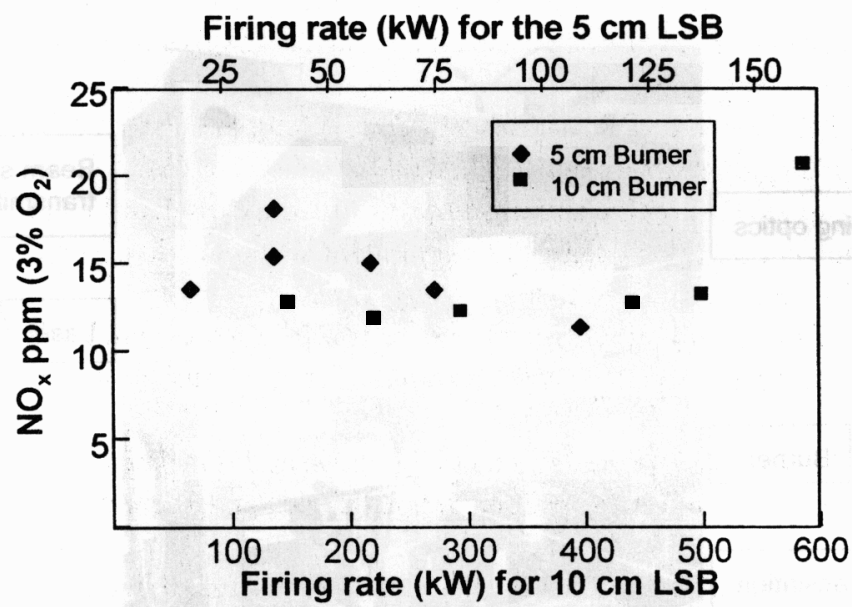

Fig. 5. NOx emission measured in a small $(5 \mathrm{~cm}$ diameter) and a large $(10 \mathrm{~cm}$ diameter) lowswirl burner. The ordinate of this plot is proportional to the exit flow velocity of the two burners

flame of Figure 2 is stabilized by a patented inner ring inserted inside the burner tube ${ }^{(5)}$. Without this ring, the conical turbulent flame cannot be established. This inner ring was developed for use in our $\mu \mathrm{g}$ experiment. Subsequent research have been conducted to test its performance in domestic furnaces and show that it can reduce the emissions of NOx to below 15 parts-per-million and also improve overall heat transfer efficiency.

The low-swirl burner shown to the right of Figure 2 is a more innovative concept than the inner ring stabilizer. Traditionally, all swirl burners operate at high swirl rates to promote the formation of a recirculation zone where the flame anchors. We found that low-swirl, without generating flow recirculation, is more effective in allowing lean premixed flame to propagate. Low swirl burners are capable of supporting very stable ultra-lean premixed combustion and is not influence by enclosures and slight changes in flow or mixture conditions ${ }^{(8)}$. Our effort to adapt this burner to water heaters of up to $150 \mathrm{KW}$ has shown them to be a economical solution to lower the emission of NOx to meet the most stringent air-quality rules for Southern California effective in 2000. We also have demonstrated that a low-swirl burner of close to 1 MW is feasible (Figure 5), producing a flame that burns close to $100 \%$ efficiency while maintaining ultra low $\mathrm{NOx}^{(7)}$. Recent rig testing has demonstrated that the low swirl flame stabilization method is also adaptable to an industrial gas turbine combustor environment.

\section{References}

(1) Bedat, B. and Cheng, R.K., Experimental Study of Premixed Flames in Intense Isotropic Turbulence, Combustion and Flame, 100 (1995), 485-494.

(2) Cheng, R.K., Shepherd, I.G., and Gokalp, I., A Comparison of the Velocity and Scalar Spectra in Premixed Turbulent Flames, Combustion and Flame, 78 (1989), 205-221.

(3) Cheng, R.K., Velocity and Scalar Characteristics of Premixed Turbulent Flames Stabilized By Weak Swirl, Combustion and Flame, 101 (1995), 1-14. 
(4) Shepherd, I.G., Cheng, R.K., and Talbot, L., Experimental Criteria For the Determination of Fractal Parameters of Premixed Turbulent Flames, Experiments in Fluids, 13 (1992), 386-392.

(5) Johnson, M.R., Kostiuk, L.W., and Cheng, R.K., A Ring Stabilizer for Lean Premixed Turbulent Flames, Combustion and Flame, 114 (1998), 594-596.

(6) Chan, C.K., et al., Freely Propagating Open Premixed Turbulent Flames Stabilized by Swirl, Twenty-fourth Symposium (International) on Combustion, The Combustion Institute, Pittsburgh, 511-518, 1992.

(7) Yegian, D.T. and Cheng, R.K., Scaling the Low Swirl Burner from $15 \mathrm{~kW}$ to $600 \mathrm{~kW}$, American Japanese Flame Research Committee International Symposium, Maui, Hawaii, 1998.

(8) Yegian, D.T. and Cheng, R.K., Development of a Lean Premixed Low Swirl Burner for Low NOx Practical Applications, Combustion Science and Technology, 139 (1998), 207227.

(9) Bedat, B. and Cheng, R.K., Effects of Buoyancy On Premixed Flame Stabilization. Combustion and Flame, 107(1996), 13-26.

(10) Cheng, R.K., Bedat, B., and Kostiuk, L.W., Effects of Buoyancy on Lean Premixed VFlames - Part I: Laminar and Turbulent Flame Structures, Combustion and Flame, 116 (1999), 360-375. 


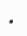

